\title{
A CASE REPORT OF PHENYTOIN AND CARBAMAZEPINE CROSS-REACTIVITY
}

\author{
BHUVANA K ${ }^{1 *}$, SARALA N ${ }^{1}$, VENKATARATHNAMMA PN ${ }^{2}$, KUMAR TN ${ }^{1}$
}

${ }^{1}$ Department of Pharmacology, Sri Devaraj Urs Medical College, Tamaka, Kolar, Karnataka, India. ${ }^{2}$ Department of Medicine, Sri Devaraj Urs Medical College, Sri Devaraj Urs Academy of Higher Education and Research, Tamaka, Kolar, Karnataka, India. *Email: drbhuvana_k@ yahoo.com

Received: 21 June 2016, Revised and Accepted: 13 July 2016

\section{ABSTRACT}

A case report of cross-reactivity between phenytoin and carbamazepine, a 63-year-old male patient was prescribed phenytoin for generalized seizures and on the $15^{\text {th }}$ day of therapy developed generalized maculopapular eruptions. Phenytoin was discontinued, and carbamazepine was administered. After 28 days, he developed fever, generalized rashes with ulcers in the oral cavity. Carbamazepine was withdrawn, and the patient was treated symptomatically.

Keywords: Phenytoin, Carbamazepine, Cross-reactivity.

(C) 2016 The Authors. Published by Innovare Academic Sciences Pvt Ltd. This is an open access article under the CC BY license (http://creativecommons. org/licenses/by/4. 0/) DOI: http://dx.doi.org/10.22159/ajpcr.2016.v9s2.13599

\section{INTRODUCTION}

Maculopapular eruptions are the most frequent undesirable reactions caused by drugs. They are usually mild and disappear spontaneously in a few days to weeks but have a potential for severe complications [1]. Timely identification and treatment are necessary. Drug hypersensitivity syndrome is an idiosyncratic, serious drug reaction that consists of a rash, fever, involvement of multiple visceral organs, and hematological abnormalities such as eosinophilia [2]. Bocquet et al. have introduced the term drug rash with eosinophilia and systemic symptoms (DRESS) syndrome. Anticonvulsants, especially those producing arene oxides on metabolism, are responsible for this syndrome [2,3]. Aromatic anticonvulsants such as phenytoin and carbamazepine produce arene oxide and are frequently implicated in DRESS syndrome [2]. Many studies have described the cross-reactivity among the aromatic anticonvulsants as a complication which occurs due to worsening of the initial features of DRESS syndrome when switching from a sensitive anticonvulsant to a cross-reactive anticonvulsant [2]. The aromatic anticonvulsants such as phenytoin, carbamazepine and phenobarbitone are first-line drugs to treat convulsions and are known to cause maculopapular reactions with a cross-reactivity among them [4]. We report a case of cross-reactivity between phenytoin and carbamazepine.

\section{CASE REPORT}

A 63-year-old male patient suffering from generalized seizures was prescribed phenytoin $300 \mathrm{mg}$ daily. He developed generalized maculopapular rashes on the $15^{\text {th }}$ day of therapy. It was mild and subsided after administration of cetirizine. Phenytoin was discontinued, and carbamazepine was prescribed $600 \mathrm{mg}$ daily in divided doses. On the $20^{\text {th }}$ day of carbamazepine therapy, the patient developed rashes, and they subsided after symptomatic therapy. He continued to take carbamazepine and after 8 days, he developed fever followed by generalized maculopapular eruptions with ulcers in the oral cavity and lips. Fig. 1a shows the maculopapular eruptions on chest and abdomen.

On examination, erythematous ulcers were observed over the lips, tongue, and buccal mucosa. Lips were swollen and face was edematous. Maculopapular eruptions were present over the entire body with no laboratory abnormalities. A diagnosis of cross-reactivity between phenytoin and carbamazepine was made. The patient was hospitalized, carbamazepine withdrawn and was treated with parenteral dexamethasone, chlorpheniramine maleate tablet, and topical calamine application. The patient responded to treatment and was discharged after a week. 2 months later, he had improved. Fig. 1b shows the healed maculopapular rashes with residual pigmentation. Patient consent and Institutional Ethics Committee approval were obtained.

\section{DISCUSSION}

The overall incidence of undesirable side effects is three times high in patients over 60 years than in younger, due to increased exposure to drugs and also altered pharmacokinetics and pharmacodynamics. Drugs can produce maculopapular eruptions (incidence $<1 \%$ ), but with phenytoin and carbamazepine, the incidence is $>5 \%$. Maculopapular eruptions are associated with fever, facial edema, and swelling of eyelids [5]. Cross-sensitivity among the aromatic anticonvulsants is $80 \%[6,7]$. Our patient had manifested with drug rash and fever but no eosinophilia as described in DRESS syndrome. Maculopapular eruption is Type IV immunological reaction which is mediated by human leukocyte antigen factors or reactive metabolites. Drug interactions due to alterations in drug metabolism, detoxification, antioxidant defenses, and immune reactivity may be involved in cross-reactivity. Approximately, $70-75 \%$ of patients manifesting with maculopapular eruptions to one aromatic anticonvulsant shows cross-reactivity to another [8]. In our patient, cross-reaction had occurred when he received carbamazepine after phenytoin. Aromatic anticonvulsants are metabolized by the cytochrome P-450 enzyme to a common
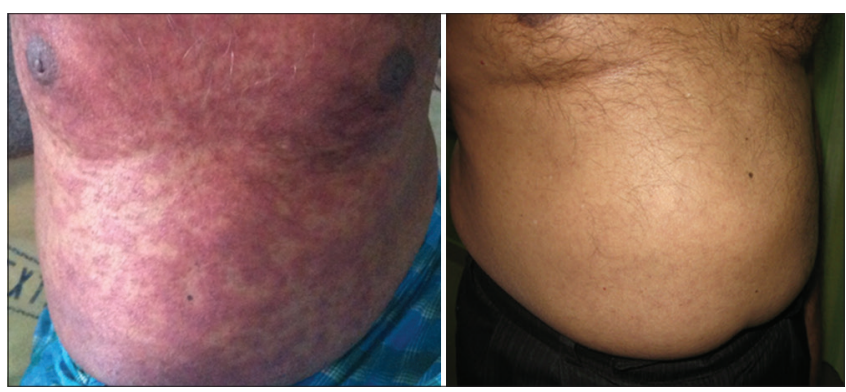

Fig. 1: (a) Maculopapular rashes on trunk. (b) Lesions healed after two months 
arene oxide metabolite which is normally detoxified by epoxide hydrolase. Genetically determined abnormalities in enzyme system resulting in inability to detoxify toxic metabolite could be the probable mechanism in the pathogenesis of DRESS syndrome $[6,7,9]$. Reactive, toxic metabolites irreversibly modify cellular proteins and cause cell damage or act as hapten to elicit an immune response $[2,4]$. Thus, both pharmacogenetic and immunologic mechanism may play an important role in anticonvulsant-induced DRESS syndrome [2]. In these patients, convulsions may have to be managed with sodium valproate [10].

\section{CONCLUSION}

Hypersensitivity to aromatic anticonvulsants if suspected, discontinue the offending drug/s and supportive therapy has to be provided. In most cases, systemic corticosteroid therapy in combination with the withdrawal of the drug may improve the situation.

\section{REFERENCES}

1. Bork K, editor. Undesirable cutaneous drug reactions. Cutaneous Side Effects of Drugs. $1^{\text {st }}$ ed. Philadelphia, PA: W.B Saunders Company; 1988. p. 29-77.

2. Kim CW, Choi GS, Yun CH, Kim DI. Drug hypersensitivity to previously tolerated phenytoin by carbamazepine-induced DRESS syndrome. J Korean Med Sci 2006;21(2):768-72.

3. Bocquet H, Bagot M, Roujeau JC. Drug-induced pseudolymphoma and drug hypersensitivity syndrome (Drug Rash with Eosinophilia and Systemic Symptoms: DRESS). Semin Cutan Med Surg 1996;15(4):250-7

4. Hirsch LJ, Arif H, Nahm EA, Buchsbaum R, Resor SR Jr, Bazil CW. Cross-sensitivity of skin rashes with antiepileptic drug use. Neurology 2008;71(19):1527-34.

5. Bork K, editor. Characteristic findings in the elderly. In: Cutaneous Side Effects of Drugs. $1^{\text {st }}$ ed. Philadelphia, PA: W.B Saunders Company; 1988. p. 12.

6. Knowles SR, Shapiro LE, Shear NH. Anticonvulsant hypersensitivity syndrome: Incidence, prevention and management. Drug Saf 1999;21:489-501.

7. Shear NH, Spielberg SP. Anticonvulsant hypersensitivity syndrome. In vitro assessment of risk. J Clin Invest 1988;82:1826-32.

8. Shear NH, Knowles SR, Shapiro L. Cutaneous reactions to drugs. In Wolff K, Golfsmith LA, Katz SI, Gilchrest BA, Paller AS, Leffell DJ, editors. Fitzpatrick's Dermatology in General Medicine. $7^{\text {th }}$ ed. New York: The McGraw-Hill Companies; 2008. p. 355-61.

9. Lee AY, Kim MJ, Chey WY, Choi J, Kim BG. Genetic polymorphism of cytochrome P450 2C9 in diphenylhydantoin-induced cutaneous adverse drug reactions. Eur J Clin Pharmacol 2004;60(3):155-9.

10. Misra UK, Kalita J, Rathore C. Phenytoin and carbamazepine cross reactivity: Report of a case and review of literature. Postgrad Med J 2003;79(938):703-4. 